\title{
Size-dependent Elastic/Inelastic Behavior of Enamel over Millimeter and Nanometer Length Scales
}

\author{
Ang $\mathrm{SF}^{1}$, Bortel $\mathrm{EL}^{1}$, Swain $\mathrm{MV}^{2,3}$, Klocke $\mathrm{A}^{4,5}, \mathrm{Sch}$ eider $\mathrm{GA}^{1 *}$ \\ ${ }^{I}$ Institute of Advanced Ceramics, Hamburg University of Technology, Hamburg \\ 21073 Germany \\ ${ }^{2}$ Biomaterials Science Research Unit, Faculty of Dentistry, University of Sydney, \\ NSW 2006 Australia \\ ${ }^{3}$ Department of Oral Sciences, University of Otago, Dunedin \\ 9054 New Zealand \\ ${ }^{4}$ Division of Orthodontics, Department of Orofacial Sciences, University of California, San Francisco, \\ CA 94143, USA \\ ${ }^{5}$ Department of Orthodontics, University Medical Center Hamburg-Eppendorf, Martinistr. 52, \\ Hamburg 20246 Germany \\ *Corresponding author. Tel: +49-40-428783037; fax: +49-40-428782647. E-mail address: \\ g.schneider@tu-harburg.de (SchneiderGA).
}

\begin{abstract}
The microstructure of enamel like most biological tissues has a hierarchical structure which determines their mechanical behavior. However, current studies of the mechanical behavior of enamel lack a systematic investigation of these hierarchical length scales. In this study, we performed macroscopic uni-axial compression tests and the spherical indentation with different indenter radii to probe enamel's elastic/inelastic transition over four hierarchical length scales, namely: 'bulk enamel' (mm), 'multiple-rod' (10's $\mu \mathrm{m})$, intra-rod' (100's nm with multiple crystallites) and finally 'single-crystallite' (10's $\mathrm{nm}$ with an area of approximately one hydroxyapatite crystallite). The enamel's elastic/inelastic transitions were observed at $0.4-17 \mathrm{GPa}$ depending on the length scale and were compared with the values of synthetic hydroxyapatite crystallites. The elastic limit of a material is important as it provides insights into the deformability of the material before fracture. At the smallest investigated length scale (contact radius $\sim 20 \mathrm{~nm}$ ), elastic limit is followed by plastic deformation. At the largest investigated length scale (contact size $\sim 1 \mathrm{~mm}$ ), only elastic then micro-crack induced response was observed. A map of elastic/inelastic regions of enamel from millimeter to nanometer length scale is presented. Possible underlying mechanisms are also discussed.
\end{abstract}

Keywords: enamel; hydroxyapatite; compression; nanoindentation; elastic/plastic transition; sizedependent

\section{Introduction}

Teeth enamel, irrespective of the host, are materials that exhibit remarkable resilience with their ability to withstand millions of loading events in the oral environment throughout a creatures lifetime. Similar to other biological materials with load bearing functions such as bone and nacre, characteristics such as hierarchical structure [1], anisotropy [2,3] and composition [4] are crucial for long-term survival of the materials. A better understanding of enamel's deformation behavior under loading is required for restorative purposes in dentistry.

The composition of human enamel contains $\sim 90 \mathrm{vol} \%$ hydroxyapatite (HAP) crystallites, $\sim 8 \mathrm{vol} \%$ water and $\sim 2 \mathrm{vol} \%$ organic matrix [5]. A schematic of enamel's hierarchical structure is shown in Fig. 1. Microstructurally, it is composed of closely-packed parallel rod-like structures also called prisms that span from the dentino-enamel junction (DEJ) to approximately $6-12 \mu \mathrm{m}$ below the tooth surface [6]. The cross section of these rods resembles the shape of keyholes with diameters of $\sim 5 \mu \mathrm{m}$. At the nanostructural level, the rods consist of HAP crystallites. Meckel et al. [7] characterized crystallites orientation in the rods by observing ultra-thin sections (500-800 $)$ of mature human enamel under electron microscopy. They identified that the crystallites within any single rod are oriented along the rod axis in the core 
region of a rod, but are gradually tilted away upon moving towards the tail of a rod, to be about $60-70^{\circ}$ inclined to the rod axis. The junctions between rods are marked by abrupt changes of crystallite orientations. Although they did not observe evidence of "interprismatic substance" between the rods, this structure prevails in the electron microscopy images from other researchers $[8,9]$. The electron microscopy images of cross-sections of human third molar enamel [8] and embryonic bovine enamel [9] show that the crystallites in the interprismatic regions appear to deviate up to $90^{\circ}$ from those of the rod cores. As proteins and water accumulate within these less dense packed transition regions they appear as distinct protein-rich structures and are called 'rod sheaths' [10]. Adult human enamel crystallites have roughly hexagonal forms and a cross section of $\sim 30 \mathrm{~nm}$ in thickness and $55-90 \mathrm{~nm}$ in width $[11,12]$. The crystallites are long, some investigators believe that they span over the entire thickness of the enamel layer [13]. The crystallites are believed to be surrounded by $1-2 \mathrm{~nm}$ of thin organic layer too [11].

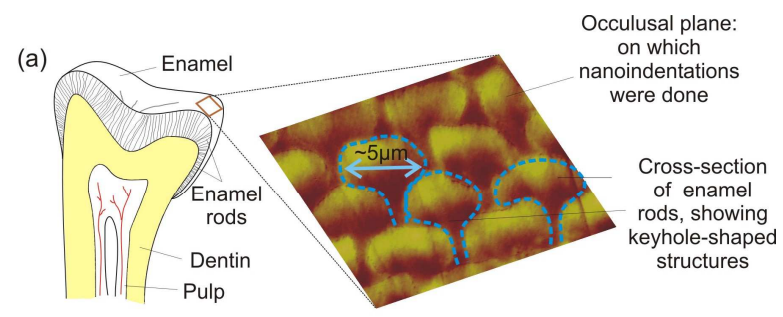

(b)

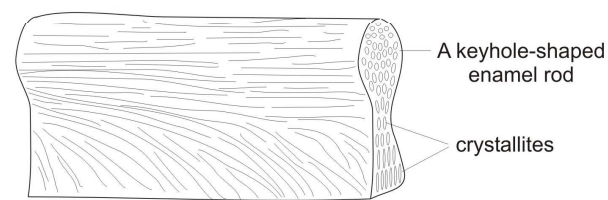

Fig. 1: Micro- and nanostructure of enamel. (a) Enamel is the outer-most layer of teeth. The enlarged section shows an occlusal plane, where enamel rods are cross-sectioned and shows keyhole-shaped structures of $\sim 5 \mu \mathrm{m}$. (b) A schematic illustration of one enamel rod and the arrangement of the $\sim 50 \mathrm{~nm}$ crystallites inside, modified from [14].

Enamel's hierarchical structure has also made analysis of its mechanical behavior complex. A profound understanding of the structure-behavior relationships necessitates its mechanical characterization at all hierarchical levels. Characterization at the nanoscale helps to probe local origins of macroscale responses. Characterization at all length scales may provide guidance as to how enamel translates the strengths derived from nanostructures and hierarchical structures to macroscale robustness.
However, currently research on enamel lacks a comprehensive assessment of the mechanical properties on most important hierarchical length scales which are namely: 'bulk enamel' (1$5 \mathrm{~mm})$, 'multiple-rod' $(\sim 50 \mu \mathrm{m})$, 'intra-rod' $(\sim 5 \mu \mathrm{m})$ and 'single-crystallite' (10-50nm). Indentation with spherical tipped indenters enables determination of the elastic/inelastic response at these various length scales because of the geometrical self similarity and the ability to select indenters with varying radii.

In this paper, we quantify human and bovine enamel's stress-strain behavior with uni-axial compression at millimeter length scale and spherical indentation with indenter radii of $3 \mathrm{~mm}$, $8.3 \mu \mathrm{m}, 63 \mathrm{~nm}$. The corresponding contact areas are bulk enamel, several rods, multiple HAP crystallites and finally approximately one HAP crystallite. Besides the elastic response we are interested in the limit of elastic deformation which corresponds to an elastic-inelastic transition. The influence of the visco-elastic response on the observed behavior will also be discussed.

\section{Theory: Indentation Stress-strain Relationships}

Indentation derived stress-strain curves were first introduced by Tabor [15], and originally developed for metals. The resultant stress-strain responses are different from uni-axial mechanical tests due to the complex 3D-stress-distribution around the indent. A spherical indenter in contact with a specimen surface is shown in Fig. 2. The indentation contact area, $A$ can be related to the indentation radius, $a$, or to the indenter radius, $R$ and the contact depth, $h_{c}$ :

$$
A=\pi a^{2}=\pi\left(2 R h_{c}-h_{c}^{2}\right)
$$

The classical Hertzian equation for elastic contact of an elastically isotropic material is given by [17]:

$$
h_{t}=\left(\frac{9}{16}\right)^{1 / 3}\left(\frac{P}{E_{r}}\right)^{2 / 3}\left(\frac{1}{R}\right)^{1 / 3}
$$

where $h_{t}$ is the total penetration depth, $P$ is the applied load and $E_{r}$ is the reduced elastic modulus.

In its elastic regime [16] which is usually always the case for the onset of loading:

$$
h_{c}=\frac{h_{t}}{2}
$$


The elastic modulus, $E$ of the specimen can be calculated by considering the compliance of the specimen and the indenter tip combined in series,

$$
E=\frac{1-v^{2}}{\left(\frac{1}{E_{r}}-\frac{1-v_{i}^{2}}{E_{i}}\right)}
$$

where $E_{i}, E$ and $v_{i}, v$ are elastic modulus and Poisson's ratio of diamond indenter and specimen respectively. For the diamond indenter $E_{i}=1140 \mathrm{GPa}$ and $v_{i}=0.07$ are used (Hysitron manual, Hysitron, USA).

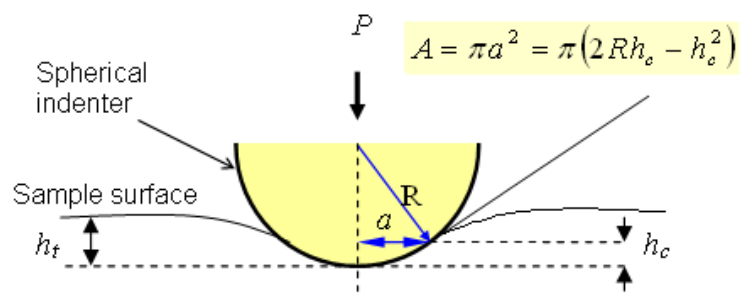

Fig. 2: A schematic diagram of an elastic contact between an ideal stiff spherical indenter and the surface of an indented specimen. $P$ is the applied load, $R$ is the radius of the spherical indenter and $a$ is the radius of the indentation area. $h_{t}$ is the total indentation depth and $h_{c}$ is the depth of the contact area. $h_{t}=2 * h_{c}$ for elastic response penetration [16].

From Tabor, the indentation stress is represented by the mean contact pressure, $P_{m}$ :

$$
P_{m}=\frac{P}{A}
$$

By assuming $h_{t}<<\mathrm{R}$, substituting Eq. $1-$ 3 into Eq. 5 gives for the elastic regime

$$
P_{m}=\left(\frac{4 E_{r}}{3 \pi}\right) \frac{a}{R}
$$

The indentation strain, $\varepsilon$ is approximated from experiment data on metals and may be approximated as follows [15]:

$$
\varepsilon=0.2 * a / R
$$

From Eq. 4 , if we neglect the term $\left(1-v_{i}^{2}\right) / E_{i}$ as it is $\sim 10$ times smaller than the term $1 / E_{r}, E$ is within $\pm 10 \%$ of $E_{r}$ for $20 \mathrm{GPa}<E_{r}<120 \mathrm{GPa}$ and $0.23<v<0.28$. Therefore in our case it is justified to approximate $E \approx E_{r}$ in Eq. 6,

$$
P_{m} \approx E *(0.4 * a / R)
$$

Note that the approximate "indentation strain" term in Eq. 8 is 2 times bigger than in Eq. 7. To avoid the ambiguity arising from the definition of indentation strain, the indentation stress-strain curves throughout this article are plotted as $P_{m}$ versus $a / R$.

\section{Materials and Methods}

\subsection{Specimen Preparation}

For uni-axial compression tests, permanent bovine mandibular incisors were used due to their larger size and amount of enamel compared to human teeth. Bovine enamel also shows very similar microstructure with human enamel in terms of rod size and shape, and also a similar amount of apatite and organic components $[18,19]$. Rectangular prisms were first cut from the labial side of bovine incisors, as shown in the upper inset in Fig. 3. With the upper surface bonded by double-sided tape on a holder, the lower surface was first polished with an abrasive paper of grit 4000, followed by diamond suspensions to $1 \mu \mathrm{m}$. The polishing steps were then repeated for the upper surface.
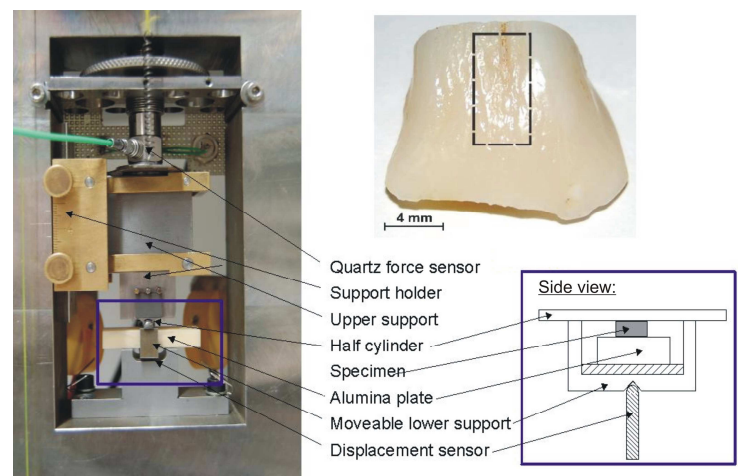

Fig. 3: Uni-axial compression device. Upper inset shows the portion of labial bovine enamel cut out for sample preparation.

Human third molar teeth were utilized for the nanoindentation. After disinfection in $0.1 \mathrm{wt} \%$ thymol, the teeth were stored in Hank's Balanced Salt Solution (HBSS, Invitrogen, USA) before sample preparation in order to minimize near surface demineralization and, subsequently, a change in mechanical properties [20]. The teeth were cut at the junction between crown and root and the root was discarded. The tooth surface facing the root was then glued onto a solid steel cylinder which was to be attached inside a steel cylinder with a hollow core. The steel cylinder 
with a hollow core acted as the polishing holder and also maintained the plane parallelism of the polished surface. The cuspal region of the tooth was first polished with an abrasive paper of grit 4000. It was further polished with diamond suspensions to $0.25 \mu \mathrm{m}$. The final polishing step was performed with silica suspension of $0.06 \mu \mathrm{m}$ (Mastermet 2, Bühler, Germany). The polished tooth was then glued face-up on a magnetic plate with wax for subsequent investigation with AFM and nanoindentation. The polished tooth surface was investigated in regions where enamel rods were oriented parallel to the nanoindentation direction.

Synthetic polycrystalline hydroxyapatite was used for comparison purposes in nanoindentation tests. The materials were provided from the Department of Materials Science and Engineering, University of Illinois at UrbanaChampaign with purity of $>99.9 \%$ and grain size of around $1 \mu \mathrm{m}$. The polishing steps were the same as those for the human third molar teeth.

\subsection{Equipment and Testing Parameters}

\section{Uni-axial compression}

The principal experimental setup for the uniaxial compression is shown in Fig. 3, modified from a previous experimental setup by Jelitto et al. [21]. The equipment parts for uni-axial compression are mounted in a very rigid metal frame. The force exerted on the sample is controlled manually. A quartz force sensor (quartz dynamic load cell 9212, Kistler Instrumente $\mathrm{GmbH}$, Germany) of high sensitivity $(-11.3 \mathrm{pC} / \mathrm{N})$ and minimal drift is used to measure the exerted force. The sample is loaded to a maximum force of $3 \mathrm{kN}$. A half cylinder, held to the upper support by magnets, is placed in between the upper support and the sample to rectify possible lack of plane parallelism of compressed sample surfaces. The displacement of the upper support is transferred via a movable lower support to an inductive position encoder (1-Weta $1 / 2 \mathrm{~mm}$, HBM, Germany) with linearity error of $< \pm 0.3 \%$, which is programmed to measure over a distance of $\pm 100 \mu \mathrm{m}$.

An alumina sample of $\sim 4 \times 5 \mathrm{~mm}^{2}$ in area and $\sim 1.5 \mathrm{~mm}$ in thickness is used to calibrate the effect of equipment deformation under compression. It is assumed that the compressibility of alumina is negligible up to $3 \mathrm{kN}$ with a pressure of $150 \mathrm{MPa}$, and the generated force-displacement response represents the equipment deformation under loading. All force-displacement curves with specimens had this equipment deformation subtracted before the stress-strain curves were computed. Compression of $2 \times 2 \times 2 \mathrm{~mm}^{3}$ aluminum cubes (AlMgSi0.5) showed reproducible $(0.2 \%)$ yield stress and displayed similar values shown in the material data sheet $(\sim 160 \mathrm{MPa})$. The uncertainty of displacement is $\pm 2 \mu \mathrm{m}$, which is $\pm 10 \%$ of $20 \mu \mathrm{m}$ displacement used in the calculation of elastic modulus, and $\pm 2 \%$ of the $100 \mu \mathrm{m}$ total displacement shown in Fig. 6(a).

\section{Nanoindentation}

The nanoindentation experiments were performed using a Triboscope indenter system (Hysitron, USA) mounted with a diamond spheroconical indenter tip (Hysitron, USA). 3 indenters were used in this study: $\mathrm{R}=8.3 \mu \mathrm{m}$, $\mathrm{R}=0.86 \mu \mathrm{m}$ and $\mathrm{R}=63 \mathrm{~nm}$. The $\mathrm{R}=63 \mathrm{~nm}$ indenter is a cube corner indenter for which the tip is assumed to be reasonably spherical at very low penetration depth $\left(h_{t}<10 \mathrm{~nm}\right)$.

The indenter tip radii were calibrated on a fused quartz sample (Hysitron, USA) $\left(E_{r}=69.6\right.$ $\mathrm{GPa}$ ) with loading curves of $P_{\max }$ ranging from 0.1 to $11 \mathrm{mN}$. More than 45 curves were used to calibrate each indenter. The initial parts of these loading curves were fitted with Eq. 2 to obtain the radius, which were appropriate to $h_{t}<20 \mathrm{~nm}$ for $8.3 \mu \mathrm{m}$ indenter, $15<h_{t}<60 \mathrm{~nm}$ for $0.86 \mu \mathrm{m}$ indenter and $h_{t}<10 \mathrm{~nm}$ for $63 \mathrm{~nm}$ indenter. These ranges were chosen because they displayed linear behavior and the limit of elastic range for the materials under investigation occurs in this region. For deeper indentations, the spheroconical shape of the tip leads to the deviation from linearity and especially for Eq. (2).

All indentation tests on human enamel were done at ambient conditions. Each series of indentations was finished within 8 hours. Using the $8.3 \mu \mathrm{m}$ indenter, one human third molar was studied with indentation loads of $5 \mathrm{mN}$ and $11 \mathrm{mN}$. The indentations were placed in the middle of the enamel rods. With the $0.86 \mu \mathrm{m}$ indenter, the HAP was studied with indentation loads to $2 \mathrm{mN}$. Using the $\mathrm{R}=63 \mathrm{~nm}$ indenter, three human third molars and the HAP sample were studied with indentation loads to $0.4 \mathrm{mN}$. The indentations on enamel using the $\mathrm{R}=63 \mathrm{~nm}$ indenter were placed at four specific micro structural locations, namely: head, center, neck and tail of the rods (Fig. 4). All indentation tests consisted of one loading and unloading cycle in 20s. All resultant curves consisted of 8000 data 
points. The load-displacement data were used to derive the indentation stress-strain curves. The reduced elastic moduli were calculated using Eq. 2 , the results are the same when it is calculated from Eq. 6. The indentation hardness, $H$, a measure of the material's resistance against permanent deformation is computed as

$$
H=\frac{P_{\max }}{A_{c}}
$$

with $P_{\max }$ the maximum load and $A_{c}$ the projected area of contact at peak load according to the experimental protocol described by Oliver and Pharr [22].

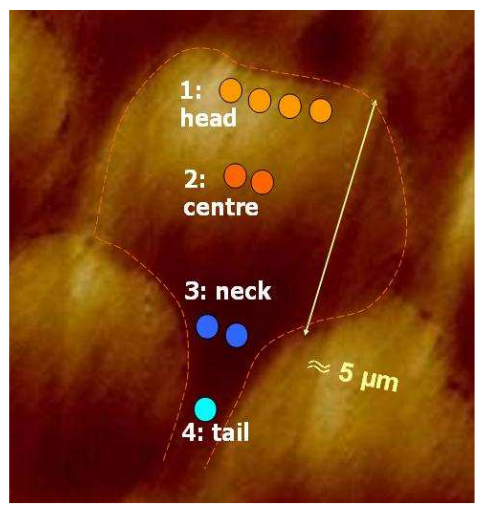

Fig. 4: The $\mathrm{R}=63 \mathrm{~nm}$ indenter was used to make indents on 4 regions inside keyholes: head, center, neck and tail.

To observe any potential cracking in the enamel from nanoindentation tests, indentations using the $\mathrm{R}=63 \mathrm{~nm}$ indenter with $1 \mathrm{mN}$ load were made. AFM with a high resolution tip (nominal tip radius $<10 \mathrm{~nm}$ ) was used to investigate the topography of the indented enamel surface [23].

\section{Results}

The radii of the indenters were calibrated as $8.3 \pm 0.9 \mu \mathrm{m}, \quad 0.86 \pm 0.03 \mu \mathrm{m} \quad$ and $\quad 63 \pm 11 \mathrm{~nm}$ respectively for the 3 indenters. For simplification, these indenters are called $\mathrm{R}=8.3 \mu \mathrm{m}$ indenter, $\mathrm{R}=0.86 \mu \mathrm{m}$ indenter and $\mathrm{R}=63 \mathrm{~nm}$ indenter throughout this article. For the $8.3 \mu \mathrm{m}$ indenter, with $P=900 \mu \mathrm{N}, h_{t}=20 \mathrm{~nm}$, the contact pressure was $\mathrm{P} / \pi^{*} \mathrm{a}^{2}=1.7 \mathrm{GPa}$, much lower than the indentation limit of elastic range of fused silica, observed as $~ 9 \mathrm{GPa}$ by using a $\mathrm{R}=7 \mu \mathrm{m}$ spherical indenter [24]. Similarly, the contact pressure under the $0.86 \mu \mathrm{m}$ indenter at $P=1400 \mu \mathrm{N}, h_{t}=62 \mathrm{~nm}$ was $\sim 8.5 \mathrm{GPa}$, which is also slightly smaller than the observed $\sim 9 \mathrm{GPa}$ by using $\mathrm{R}=0.86 \mu \mathrm{m}$ spherical indenter [24]. There- (a)

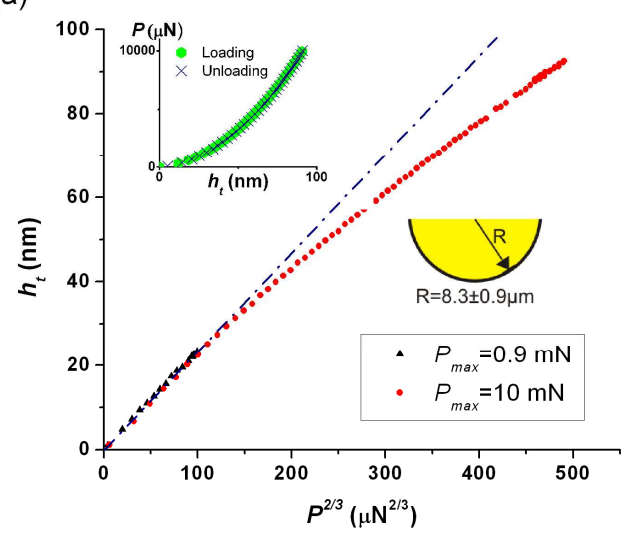

(b)

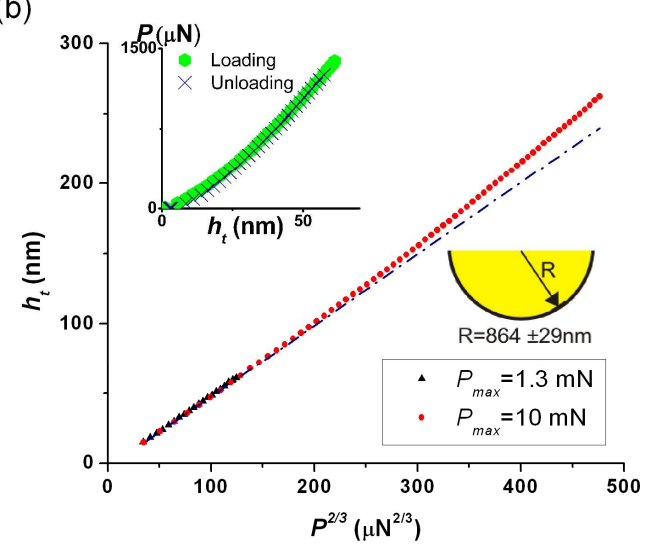

(c)

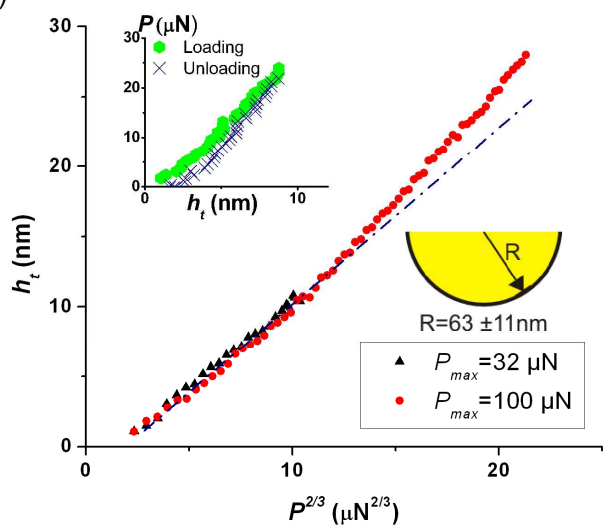

Fig. 5: Indenter radii calibration. The range of $h_{t}$ versus $P^{2 / 3}$ curves used for radii calibration for (a) $\mathrm{R}=8.3 \mu \mathrm{m}$ indenter $\left(h_{t}<20 \mathrm{~nm}\right),(\mathbf{b}) \mathrm{R}=0.86 \mu \mathrm{m}$ indenter $\left(15<h_{t}<60 \mathrm{~nm}\right)$ and (c) $\mathrm{R}=63 \mathrm{~nm}$ indenter $\left(h_{t}<10 \mathrm{~nm}\right)$ show linear behaviors. The curves deviate from the linear relation at a higher total penetration depth. (Inset: The load-displacement curves that include the range of $h_{t}$ used for radii calibration. The unloading curve overlaps with the loading curve for $\mathrm{R}=8.3 \mu \mathrm{m}$ indenter and $\mathrm{R}=0.86 \mu \mathrm{m}$ indenter, thus indicates no or negligible plasticity for the range of penetration depth used for radii calibration. The load-displacement curve for $\mathrm{R}=63 \mathrm{~nm}$ indenter show a small hysteresis.)

fore, the deviations of the measured data from the linear fit in Fig 5(a) and (b) are 
(a)

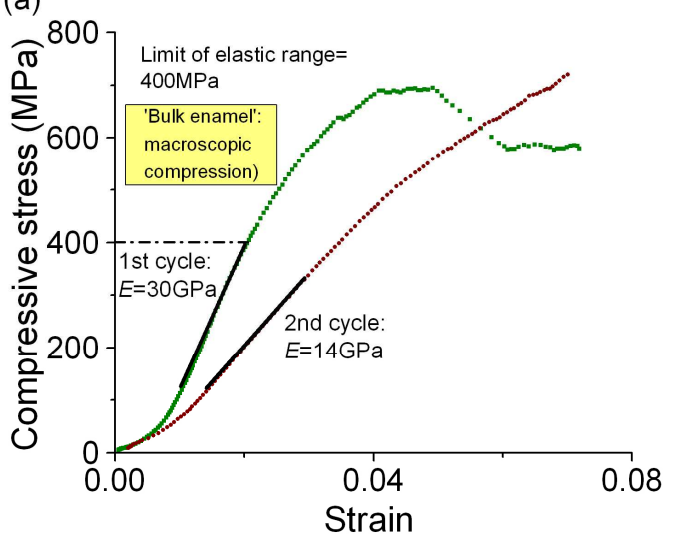

(c)

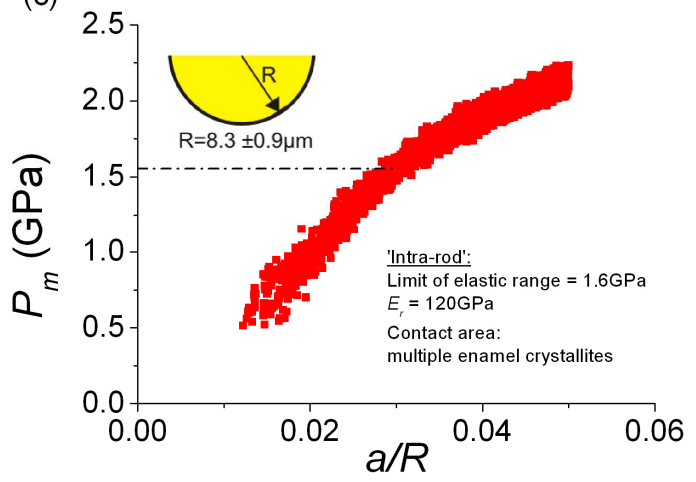

(b)

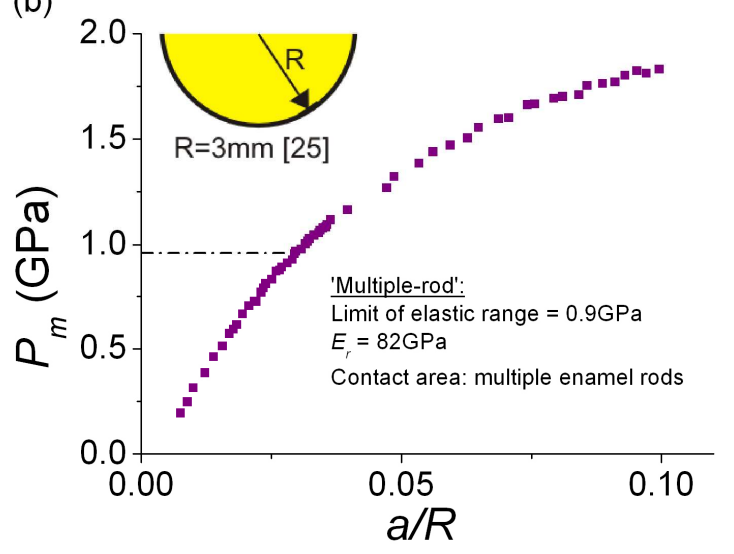

(d)

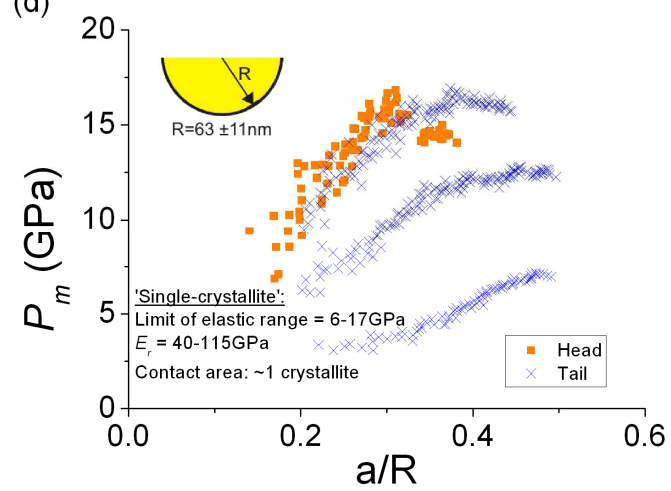

Fig. 6: Enamel's stress-strain curves. (a) Uni-axial compressive stress-strain curves for bovine enamel. Indentation stress-strain curves of enamel with (b) $\mathrm{R}=3 \mathrm{~mm}$ indenter [25] (c) $\mathrm{R}=8.3 \mu \mathrm{m}$ indenter and (d) $\mathrm{R}=63 \mathrm{~nm}$ indenter. Depending on the contact areas, these length scales are called (a) 'bulk enamel' (b) 'multiple-rod' [25], (c) 'intra-rod' with multiple crystallites and (d) 'single-crystallite'.

interpreted as a change of the tip shape rather than inelastic deformation of fused silica. The contact pressure for the $\mathrm{R}=63 \mathrm{~nm}$ indenter at $P=32 \mu \mathrm{N}, h_{t}=11 \mathrm{~nm}$ is $\sim 15 \mathrm{GPa}$, higher than the typically observed limit of elastic range. The contact pressure under the same indenter at $P=2 \mu \mathrm{N}, h_{t}=1 \mathrm{~nm}$ is calculated as $10 \mathrm{GPa}$. The fused quartz sample was already deformed plastically under the indenter at such a small penetration depth. That is why the loaddisplacement curve shown as an inset in Fig. 5(c) has a hysteresis, and that the elastic response of Eq. 2 could no longer be assumed. Since the $h_{t}$ versus $P^{2 / 3}$ curve in Fig. 5(c) displays reasonably linear behavior in the calibrated region, we believe the calibrated $63 \pm 11 \mathrm{~nm}$ is not affected by the inelastic deformation of fused quartz.

After the final polishing steps, the achieved surface roughness for the bovine enamel rectangular prisms for compression test is $<5 \mu \mathrm{m}$. The surface roughness here refers to the distance of the highest peak and the lowest valley of the contacted surface during tests. Due to the difficulties involved in specimen preparation, only stress-strain curves of one satisfactory sample with a dimension of $\sim 2 \times 2 \mathrm{~mm}^{2}$ in area and $\sim 1 \mathrm{~mm}$ in thickness is presented in this article. Many samples had pre-existing cracks (observed under a light microscope) or were too thin after appropriate surface roughness was achieved. The achieved surface roughness after polishing for nanoindentation samples (both human enamel and synthetic HAP) is $<1 \mathrm{~nm}$.

The stress-strain curves from two uni-axial compression loadings, together with indentation stress-strain curves of enamel are plotted in Fig. 6(a), (c) and (d). The data from spherical indentation tests on enamel by Staines et al. [25] using $\mathrm{R}=3.125 \mathrm{~mm}$ indenter were extracted and re-plotted as $P_{m}$ versus $a / R$ in Fig. 6(b). The limit of elastic range is approximated when the curve deviates from linearity.

For macroscopic compression of bovine "bulk enamel", the stress-strain curve of the first loading indicates a limit of elastic range at around $\sim 400 \mathrm{MPa}$. The initial stress-strain curve firstly exhibits a linear elastic response with a compression modulus of $\sim 30 \mathrm{GPa}$, then deformed inelastically with decreased stiffness (Fig. 6(a)). It reached the maximum stress of around $\sim 680 \mathrm{MPa}$ without ultimate catastrophic fracture. Instead, it exhibited progressive damage with a 
jagged curve behavior at nearly constant stress at $\sim 680 \mathrm{MPa}$. This is followed by another jagged curve at a lower stress level at $\sim 580 \mathrm{MPa}$. Upon unloading followed by immediate reloading, the specimen first deformed elastically at a decreased elastic modulus of $\sim 14 \mathrm{GPa}$, reached a similar limit of elastic range as in the first loading, and was able to attain similar ultimate strength achieved in the first loading.

For indentation tests on enamel, the limit of elastic range were observed as $\sim 0.9 \mathrm{GPa}$ for 'multiple-rod' $\quad(a \sim 90 \mu \mathrm{m}$ with the $\mathrm{R}=3 \mathrm{~mm}$ indenter, $\left.h_{\tau} \sim 3 \mu \mathrm{m}\right)$ [25], $1.6 \mathrm{GPa}$ for 'intra-rod' with multiple crystallites $(a \sim 250 \mathrm{~nm}$ with the $\mathrm{R}=8.3 \mu \mathrm{m}$ indenter, $h_{\tau} \sim 7 \mathrm{~nm}$ ), $6-17 \mathrm{~Pa}$ for 'singlecrystallite' with a contact area of approximately one crystallite $(a=20 \mathrm{~nm}$ with the $\mathrm{R}=63 \mathrm{~nm}$ indenter, $\left.h_{\tau} \sim 3-10 \mathrm{~nm}\right)$. The calculated reduced elastic moduli are $E_{r}=82 \mathrm{GPa}(\mathrm{R}=3 \mathrm{~mm}$ indenter $)$, $E_{r}=120 \mathrm{GPa} \quad(\mathrm{R}=8.3 \mu \mathrm{m} \quad$ indenter $) \quad$ and $E_{r}=76 \pm 18 \mathrm{GPa}(\mathrm{R}=63 \mathrm{~nm}$ indenter $)$. Fig. $6(\mathrm{c})$ is a collective response from all indentations with the $\mathrm{R}=8.3 \mu \mathrm{m}$ indenter. Due to the large number of indentation curves with the $\mathrm{R}=63 \mathrm{~nm}$ indenter at all 4 regions inside keyhole, only some curves were plotted in Fig. 6(d) to illustrate overall behaviors. The indentation stress-strain curves in Fig. 6(b)-(d) first deformed elastically, and then appeared to soften.

Under the $\mathrm{R}=63 \mathrm{~nm}$ indenter, the collective mean values and the standard deviations of reduced elastic moduli, indentation hardness and limit of elastic range of enamel of all regions are $76 \pm 18 \mathrm{GPa}, 5.7 \pm 0.3 \mathrm{GPa}$ and $12 \pm 3 \mathrm{GPa}$.

The synthetic HAP specimen show mean values of $E_{r}=120 \pm 6 \mathrm{GPa}, H=10 \pm 1 \mathrm{GPa}$ and a limit of elastic range $=11 \pm 2 \mathrm{GP}$ with the $\mathrm{R}=0.86 \mu \mathrm{m}$ indenter. For nanoindentation with the $\mathrm{R}=63 \mathrm{~nm}$ indenter, the synthetic HAP specimen show mean values of $E_{r}=129 \pm 13 \mathrm{GPa}, H=10 \pm 1 \mathrm{GPa}$ and a limit of elastic range $=20 \pm 2 \mathrm{GPa}$. Examples of the curves are shown in Fig.7. With the same $\mathrm{R}=63 \mathrm{~nm}$ indenter the $E_{r}$ and limit of elastic range of the synthetic HAP are about $40 \%$ higher than the average values of enamel.

\section{Discussion}

To illustrate the reality, the limit of elastic range versus the corresponding contact radius for both enamel and synthetic HAP are plotted in Fig. 8. The limit of elastic range of HAP $(\sim 7 \mathrm{GPa})$, probed by using $\mathrm{R}=10 \mu \mathrm{m}$ indenter by $\mathrm{He}$ and Swain [26] is also included in the figure. With the reported reduced elastic modulus of HAP of $130 \mathrm{GPa}$, the limit of elastic range of $\sim 7 \mathrm{GPa}$ and

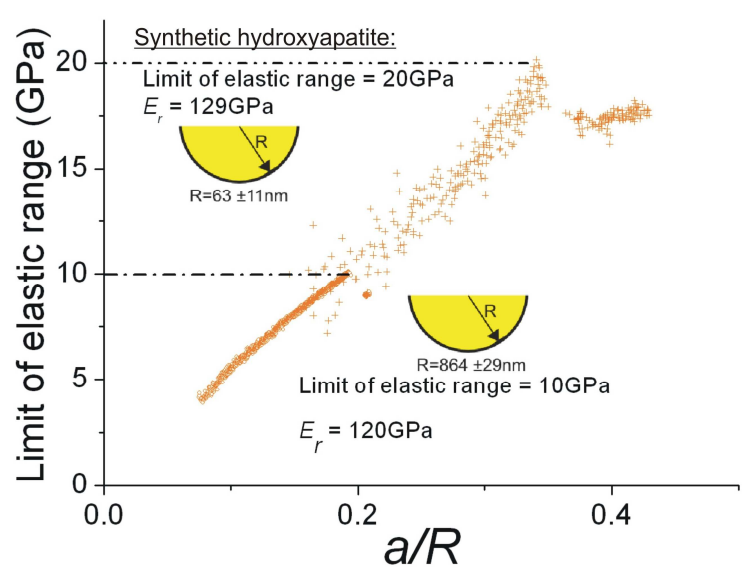

Fig. 7: Indentation stress-strain curves of synthetic $\mathrm{HAP}$ with $\mathrm{R}=0.86 \mu \mathrm{m}$ indenter and $\mathrm{R}=63 \mathrm{~nm}$ indenter.

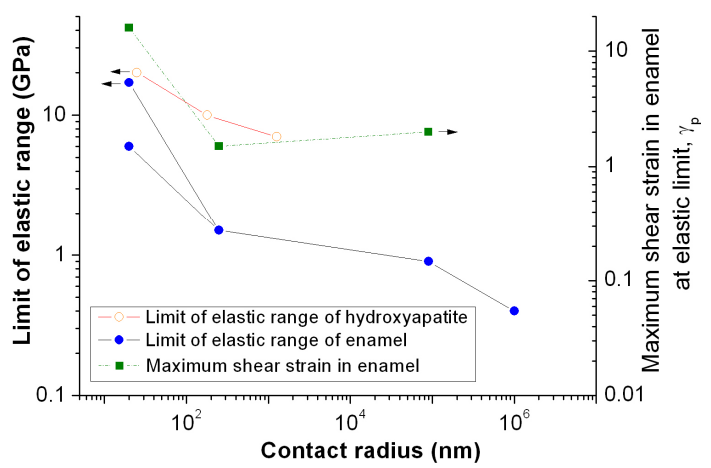

Fig. 8: Decreasing limit of elastic range of enamel and synthetic HAP with increasing length scales. The right hand side $\mathrm{Y}$-axis is the maximum shear strain in enamel at elastic limit calculated according to Eq. 12.

$\mathrm{R}=10 \mu \mathrm{m}$ introduced into Eq. 6 , the contact radius is calculated as $\sim 1270 \mathrm{~nm}$. The limits of elastic range of enamel are always smaller than of synthetic HAP for contact radii up to $1000 \mathrm{~nm}$. With increasing length scale, the limits of elastic range of both materials decrease. Such behavior in synthetic HAP is attributed to an indentation size effect based on geometrically necessary dislocations $[27,28]$. The underlying reason of such behavior in enamel is more complex due to its heterogeneous and hierarchical structure.

For the smallest contact radii of $20 \mathrm{~nm}$, the length scale of 'single-crystallite', the enamel data scatter strongly, but the highest limit of elastic range value is close to the value of pure HAP (Fig. 8). It can be concluded therefore that in some of these measurements in enamel the indenter measures the mechanical response of a single HAP crystallite. In addition it can be concluded that even at these very small contact radii, the response may not always only include HAP crystallites within the enamel.

The lower limit of elastic range values, down to approximately $6 \mathrm{GPa}$ for contact radii of $20 \mathrm{~nm}$, 
is likely to be related to the organic material separating the HAP crystallites, and will be discussed in more detail later. The next measured length scale 'intra-rod' corresponds to contact radii of $\sim 250 \mathrm{~nm}$ which means that the mechanical probing is within one keyhole. The corresponding limit of elastic range of $1.6 \mathrm{GPa}$ shows only limited scatter of $\pm 0.1 \mathrm{GPa}$. Hence, enamel appears to be very homogeneous at this length scale. The next length scale 'multiple-rod' corresponds to a contact radius of $\sim 90 \mu \mathrm{m}$ which means that the mechanical probing averages over several keyhole units. The corresponding elastic limit is only $0.9 \mathrm{GPa}$, which is again small, but still double the value of the compression test. Therefore it is very obvious that every hierarchical structure of enamel has a different mechanical response. The explanation of these different mechanical responses is a task for future research. Possible non-linear mechanisms of inelastic deformation are extension and breakage of protein layers, interfacial slippage, viscoelastic effects, all of which may lead to rotations of the HAP crystallites or cracks in them. These will be considered later based on our experimental findings.

Fig. 9 shows a plot of the limit of elastic range versus reduced elastic modulus measured for the length scale of 'single-crystallite' ( $\mathrm{R}=63 \mathrm{~nm}$ indenter) for all four specified regions (head, center, neck, tail) inside the enamel keyhole structure. It is obvious that the limits of elastic range even within the same region in the keyhole scatter considerably. This is not caused by measurement errors because measurements with the same indenter on synthetic HAP showed a maximum of $10 \%$ standard deviations from the mean values. On the other hand an approximately linear relationship is observed between the elastic limit values and the reduced Young's modulus. Because all measurements were performed within a keyhole, changes of the HAP orientation or compositional changes result in these strong variations. While variations of Young's modulus of HAP between 127 and $162 \mathrm{GPa}$ have been shown [29], they do not explain the very low $E_{r}$ values measured. In addition, large $E_{r}$ variations were measured at the same locations inside the keyholes, with identical HAP crystallite orientations observed. Therefore, it is most probable that compositional changes or the volume fraction of mineral/protein are the source of the observed variations. Applying the equation from $\mathrm{Ji}$ and Gao [3], the measured modulus, $E$, can be related to the volume fractions of minerals, $V_{m}$.

$$
V_{m}=\frac{-\left(4 E_{m} E-G_{p} \rho^{2} E\right)+\sqrt{\left(4 E_{m} E-G_{p} \rho^{2} E\right)^{2}+16 G_{p} \rho^{2} E_{m}^{2} E}}{2 G_{p} \rho^{2} E_{m}}
$$

with , $E_{m}$ the elastic modulus of the minerals, $G_{p}$ the shear modulus of protein and $\rho$ the aspect ratio of the crystallites. Since $E \approx E_{r}$ as explained in the previous section, we used $E=40-115 \mathrm{GPa}$ (Fig. 9), $G_{p}=0.1 \mathrm{GPa}$ [30], $\rho=100$ and $E_{m}=129 \mathrm{GPa}$ (Fig. 7), and found that the involved $V_{m}$ ranged from 0.48 to 0.93 , as plotted in Fig. 9. When $\rho=30$ [31] is assumed, $V_{m}$ is found to range from 0.79-0.98. Despite the influence of the assumed $\rho$ on the calculated $V_{m}$, it is obvious that pronounced nanoscale heterogeneity in enamel prevails at lengths scales of $40 \mathrm{~nm}$. Such nanoscale heterogeneity has been proposed as an effective energy dissipation strategy in biomineralized tissues [32].

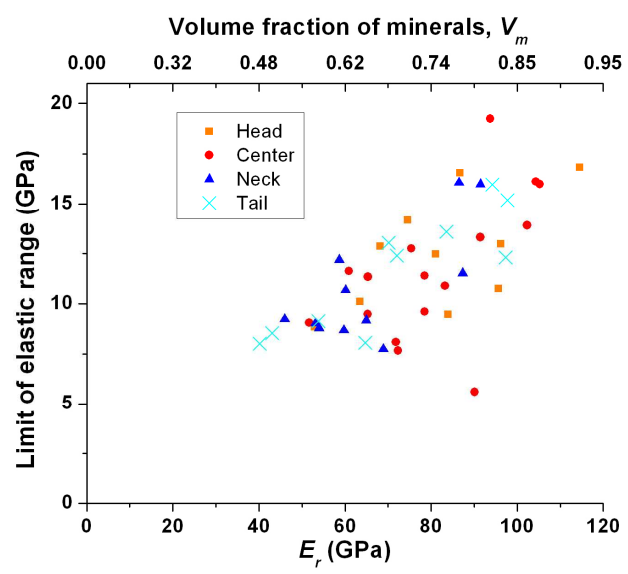

Fig. 9: Limit of elastic range versus reduced elastic modulus, $E_{r}$ (bottom x-axis) and $V_{m}$ (top x-axis) for four regions inside enamel keyholes (head, center, neck, tail) $(\mathrm{R}=63 \mathrm{~nm})$. There is seemingly a linear correlation between both properties.

\section{Possible mechanisms for non-linear deformation in enamel}

\section{Non-linear extension of protein layers}

On the possible causes of the observed limit of elastic range in enamel, non-linear extension of protein layers is hypothesized to occur before the others such as frictional sliding and cracking. The maximum shear strain in the protein layer, $\gamma_{p}$ can be calculated using a model $[33,34]$ (Fig. $10)$ : 


$$
\gamma_{p}=\frac{\left(h_{m}+h_{p}\right) \tan \theta}{h_{p}}
$$

with the maximum shear strain $\gamma_{p}$ in the protein layer, $h_{m}$ and $h_{p}$ the thickness of the enamel rod or crystallite and protein layer depending on the length scales investigated, $\theta$ the contact angle between the indenter and the surface (Fig. 11). Since $\tan \theta=a / \mathrm{R}$,

$$
\gamma_{p}=\frac{\left(h_{m}+h_{p}\right)}{h_{p}} \cdot\left(\frac{a}{R}\right)
$$

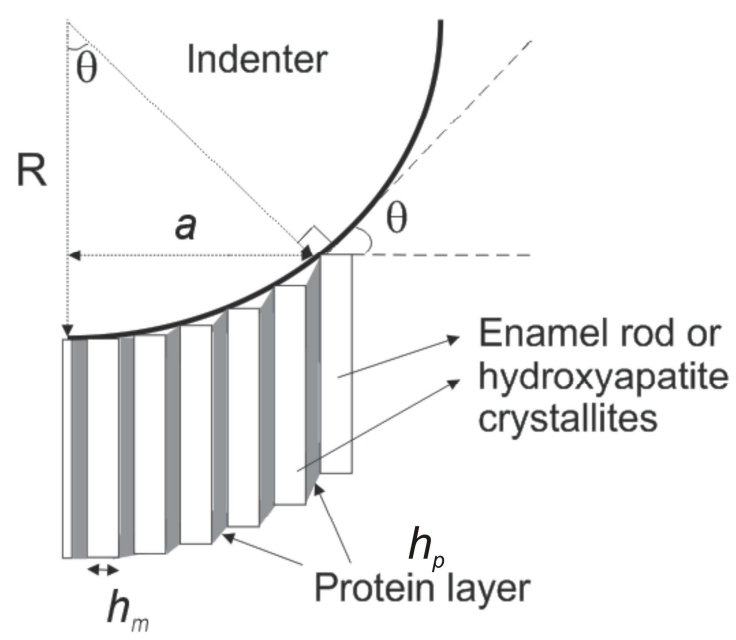

Fig. 10: Schematic illustration of enamel deformation induced by a spherical indenter. It is assumed that the deformation is completely due to the shear deformation of the protein layer.

Using the above model for multiple enamel rods of $h_{m}=5 \mu \mathrm{m}$ and a protein layer in between them of $h_{p}=70 \mathrm{~nm}$ the corresponding $\gamma_{p}$ is calculated as $\sim 2$ for the elastic limit with the $3 \mathrm{~mm}$ radius indenter [25]. For indentation involving multiple enamel crystallites within one enamel rod, $h_{m}=50 \mathrm{~nm}$ is the thickness of one crystallite and $h_{p}=1 \mathrm{~nm}$ is the thickness of the protein layer. The corresponding $\gamma_{p}$ at the elastic limit for $\mathrm{R}=8.3 \mu \mathrm{m}$ indenter and $\mathrm{R}=63 \mathrm{~nm}$ indenter are calculated as $\sim 1.5$ and $\sim 16$ respectively. These values are plotted as the second Y-axis in Fig. 8. In order to estimate a reasonable elastic stretching limit for proteins in enamel tropocollagen is used as a reference. The strain limit of covalent bond stretching (after that molecular fracture occurs) in a single tropocollagen molecule is 0.5 [35]. This is consistent with macroscopic tensile stress-strain measurements on protein tissues such as horn (mainly keratin), tendon and ligament (mainly collagen), where the tensile strain limit is usually 0.5 or less [36-38]. The above calculated values are much higher than this elastic limit of 0.5 . As a consequence it is very probable that the outermost protein layer at the border of the contact especially near the sample surface already deforms non-linearly or even breaks before the elastic limits of enamel were detected by the indentation tests. Shear deformation of protein layers and seemingly breakage of some protein backbone between crystallites under indentation has been identified in a crosssectional TEM view below a $500 \mathrm{mN}$ Berkovich indent in enamel [39].

\section{Viscoelasticity}

The influence of viscoelasticity is also considered. In the compression test, the decreased elastic modulus in the second loading is unlikely to be dominated by any viscoelastic effect. In a viscoelastic structure, the first loading would squeeze out the soft substance inside the channels between inorganic minerals, as illustrated in a previous study [40]. Before its recovery, a structure would show stiffer behavior upon second loading and not decreased elastic modulus, observed in Fig. 6(a).

In a recent nanoindentation study by Guidoni et al. [41], the creep displacement of enamel shows a displacement rate of $0.33 \mathrm{~nm} / \mathrm{s}$ under a constant load of $5 \mathrm{mN}$ using a Berkovich indenter. Such a creep effect is expected to be less significant for the blunter $8.3 \mu \mathrm{m}$ spherical, with which the limit of elastic range happens within the first second of the present experiment. For the cube corner indenter, a creep response of $0.5 \mathrm{~nm} / \mathrm{s}$ was recorded under a constant load of $5 \mathrm{mN}$ on atmospherically dry enamel [41]. Even at such a high load $(5 \mathrm{mN})$, the creep response accounted for only $<20 \%$ of the displacement involved in this study when the limit of elastic range is observed. Therefore, the effect of creep when the load is smaller than $25 \mu \mathrm{N}$ (the load when the limit of elastic range is observed in enamel with $\mathrm{R}=63 \mathrm{~nm}$ indenter) is expected to be insignificant.

\section{Cracking}

Detailed investigations of the enamel surface with high resolution AFM around indentations by the $\mathrm{R}=63 \mathrm{~nm}$ indenter (a cube corner indenter) did not reveal any kind of surface cracking within the resolution of our system (not shown here). This is probably also true for the 
indentation by $\mathrm{R}=8.3 \mu \mathrm{m}$ indenter which is blunter. The $E_{r}$ by $\mathrm{R}=8.3 \mu \mathrm{m}$ indenter is high $\left(E_{r}=120 \mathrm{GPa}\right)$ and may also be an indication of the absence of cracking. For $\mathrm{R}=3 \mathrm{~mm}$ indenter, it is unclear whether the lower $E_{r}(82 \mathrm{GPa})$ in comparison to the $\mathrm{R}=8.3 \mu \mathrm{m}$ indenter and $\mathrm{R}=63 \mathrm{~nm}$ indenter is due to cracking or the presence of thicker protein sheath for shearing. Nevertheless, all the indentation stress-strain curves (length scale $<200 \mu \mathrm{m}$ ) exhibited elastic/plastic behaviors. This may also be assisted by the greater constraint provide by the surrounding elastic material about indentation contact area. In contrast, the stress-strain curve on a macroscopic scale (length scale $>1 \mathrm{~mm}$ ) showed elastic/micro-crack induced damage behavior, which is most probably due to the cracking in enamel. Based on our findings, it appears that when a small volume is involved, plastic deformation is the major form of deformation when enamel exceeds the limit of elastic range. Whereas when a big volume is involved, micro-crack induced damage happens beyond the elastic limit.

A map of elastic/inelastic regions for enamel is proposed in Fig. 11. At the smallest studied length scale, when stress increases, the elastic region of enamel is followed by the plastic region, which might be caused by frictional sliding between crystallites, protein detachment from crystallites or deformation inside hydroxyapatite crystallites, since the proteins are not able to carry the load. If very high stress happened at these small length scales, microcrack induced damage will ensue. The boundary between the plastic and the micro-crack induced damage regions for length scales of $<100 \mu \mathrm{m}$ are estimations from the elastic/inelastic transition data of synthetic hydroxyapatite. With increasing length scale, the role of proteins might be more significant and result in a decreased limit of the elastic range. However, after a certain length scale, for example at a contact radius of $1 \mathrm{~mm}$, when the stress increases, the elastic region is followed directly by micro-crack induced damage.

Lastly, the behavior of enamel even at macroscopic scale showed desirable characteristics for a load-bearing structure. As shown in Fig. 6(a), the bovine enamel rectangular prism is deformed in a progressive damage manner, which was also observed earlier in the compressive stress-strain curves of bone [42]. The load-bearing capability was observed to remain even beyond the ultimate strength, indicating the inherent crack damage tolerance of

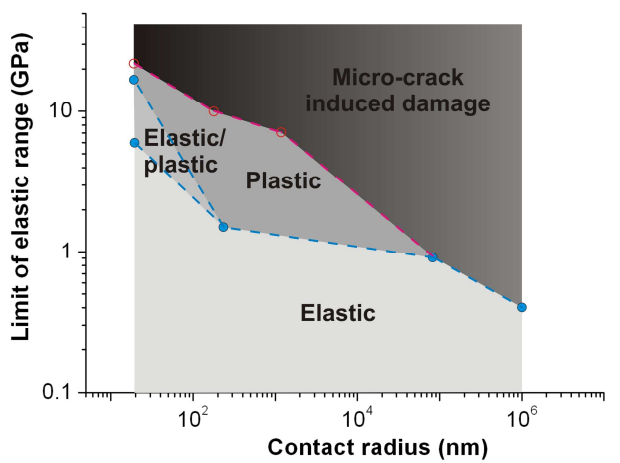

Fig. 11: A map of regions of the most probable deformation behaviors of enamel: elastic, plastic or micro-crack induced damage behavior. At the smallest investigated length scale, plastic behavior ensued after elastic deformation. However, for the biggest investigated length scale, micro-crack induced damage occurs beyond the elastic limit.

the structure instead of failing catastrophically. The stress-strain response associated with the second loading shows a decreased elastic modulus, which could be attributed to substantial microcrack damage resulting from the first loading.

\section{Conclusions}

A comprehensive assessment of the elastic/inelastic behaviors in enamel for the different lengths scales is presented (Fig. 11). At the smallest length scale, plastic deformation occurs beyond the limit of elastic range, and is unlikely to be caused by proteins alone. At the biggest length scale, micro-crack induced damage ensued after the limit of elastic range was reached. The limit of elastic range of enamel is $0.4-17 \mathrm{GPa}$ from millimeter to nanometer length scales. These length scales encompass essential hierarchical levels of enamel which are 'bulk enamel' $(a \sim 1 \mathrm{~mm}), \quad$ 'multiple-rod' $(a \sim 90 \mu \mathrm{m})$, 'intra-rod' $(a \sim 250 \mathrm{~nm})$ and 'singlecrystallite' $(a \sim 20 \mathrm{~nm})$. The macroscopic compression test results show that enamel is capable to deform in a progressive damage (saw tooth) manner in the inelastic region and also retain its load bearing capability beyond the ultimate strength. The contact loading at the $40 \mathrm{~nm}$ length scale revealed local heterogeneity.

\section{Acknowledgement}

The authors wish to express gratitude to German Research Foundation for financial support. Special thanks are extended to Dr. Rami Farah from the University of Otage, Assist. Prof. Stefan 
Habelitz and Dr. Neda Meshkin from University of California, San Francisco in the early phase of compression sample preparations. We also appreciate Dr. Hans Jelitto's from Hamburg University of Technology for his assistance in the construction of the compression device.

\section{References}

1. Fratzl P, Weinkamer R, Nature's hierarchical materials. Prog Mater Sci 2007;52(8):1263-1334.

2. $\mathrm{Xu}$ HHK, Smith DT, Jahanmir S, Romberg E, Kelly JR, Thompson VP, Rekow ED. Indentation damage and mechanical properties of human enamel and dentin. J Dent Res 1998;773:472480.

3. Ji B, Gao H. Mechanical properties of nanostructure of biological materials. J Mech Phys Solids 2004;52:1963-1990.

4. Spears IR. A three-dimensional finite element model of prismatic enamel: a re-appraisal of the data on the Young's modulus of enamel. J Dent Res 1997;76(10):1690-1697.

5. Healy KE. Dentin and enamel. In: Black J, Hastings G, editors. Handbook of biomaterials properties. London: Chapman \& Hall, 1998, p. 25.

6. Gray H, Bannister LH, Berry MM, Williams PL. Gray's anatomy: The anatomical basis of medicine \& surgery. 38th ed. New York: Churchill Livingstone; 1995, p. 1710.

7. Meckel AH, Griebstein WJ, Neal RJ. Structure of mature human dental enamel as observed by electron microscopy. Arch Oral Biol 1965;10:775-783.

8. Bajaj D, Arola DD. On the R-curve behavior of human tooth enamel. Biomaterials 2009;30:4037-4046.

9. Glimcher ML, Daniel EJ, Travis DF, Kamhi S. Electron optical and X-ray diffraction studies of the organization of the inorganic crystals in embryonic bovine enamel. J Ultrastruct Res 1965;50(Supp 7):1-77.

10. Maas MC, Dumont ER. Built to last: the structure, function and evolution of primate dental enamel. Evol Anthrop 1999;8:133-152.

11. Frazier PD. Adult human enamel: an electron microscopic study of crystallite size and morphology. J Ultrastruct Res 1968;22:1-11.

12. Daculsi G, Kerebel B. High-resolution electron microscope study of human enamel crystallites: size, shape, and growth. J Ultrastruct Res 1978;65:163-172.

13. Nanci A. Ten Cate's oral histology: development, structure, and function. St. Louis: Mosby; 2003.

14. Moss-Salentijn L, Hendricks-Klyvert M. Dental and oral tissues; an introduction. Philadelphia: Lea \& Febiger; 1985, p. 236.

15. Tabor D. The Hardness of Metals. Oxford: Clarendon Press; 1951.
16. Fischer-Cripps AC. Introduction to contact mechanics (Mechanical engineering series). New York: Springer-Verlag Inc.; 2000, p. 42.

17. Hertz HR. Miscellaneous Papers. London: Macmillan; 1896.

18. Oesterle LJ, Shellhart WC, Belanger GK. The use of bovine enamel in bonding studies. Am J Ortho 1998;114:514-520.

19. Sanches RP, Otani C, Damiao AJ, Miyakawa W. AFM characterization of bovine enamel and dentine after acid etching. Micron 2009;40:502506.

20. Habelitz S, Marshall GW, Balooch M, Marshall SJ. Nanoindentation and storage of teeth. J Biomech 2002;35:995-998.

21. Jelitto H, Felten F, Swain MV, Balke H, Schneider GA. Measurement of the total energy release rate for cracks in PZT under combined mechanical and electrical loading. J Appl Mech 2007;74:1197-1211.

22. Oliver WC, Pharr GM. An improved technique for determining hardness and elastic modulus using load and displacement sensing indentation experiments. J Mater Res 1992;7(6):1564-1583.

23. Scholz T, McLaughlin KK, Giuliani F, Clegg WJ. Espinoza-Beltrán FJ. Nanoindentation initiated dislocations in barium titanate $\left(\mathrm{BaTiO}_{3}\right)$. Appl Phys Lett 2007;91:062903.

24. Bushby AJ, Dunstan DJ. Plasticity size effects in nanoindentation. J Mater Res 2004;19(1):137142.

25. Staines M, Robinson WH, Hood JAA. Spherical indentation of tooth enamel. $\mathrm{J}$ Mater Sci 1981;16:2551-2556.

26. He LH, Swain MV. Enamel - a "metallic-like" deformable biocomposite. J Dent 2007;35:431437.

27. Nix WD, Gao H. Indentation size effects in crystalline materials: A law for strain gradient plasticity. J Mech Phys Solids 1998;46(3):411425.

28. Swadener JG, George EP, Pharr GM. The correlation of the indentation size effect measured with indenters of various shapes. J Mech Phys Solids 2002;50(4):681-694.

29. Viswanath B, Raghavan R, Ramamurty U, Ravishankar N. Mechanical properties and anisotropy in hydroxyapatite single crystals. Scr Mater 2007;57:361-364.

30. Xie ZH, Swain MV, Swadener G. Munroe P, Hoffman, M. Effect of microstructure upon elastic behavior of human tooth enamel. J Biomech 2009;42(8):1075-1080.

31. Zhou J, Hsiung LL. Biomolecular origin of the rate-dependent deformation of prismatic enamel. Appl Phys Lett 2006;89:051904.

32. Tai K, Dao M, Suresh S, Palazoglu A, Ortiz C. Nanoscale heterogeneity promotes energy dissipation in bone. Nat Mater 2007;6:454-462.

33. He LH, Swain MV. Contact induced deformation of enamel. Appl Phys Lett 2007;90:171916. 
34. Ang SF, Scholz T, Klocke A, Schneider, GA. Determination of the elastic/plastic transition of human enamel by nanoindentation. Dent Mater 2009;25(11):1403-1410.

35. Buehler MJ, Wong SY. Entropic elasticity controls nanomechanics of single tropocollagen molecules. Biophys J 2007;93:37-43.

36. Druhala M, Feughelman M. Dynamic mechanical loss in keratin at low temperatures. Colloid Polym Sci 1974;252:381-391.

37. Meyers MA, Chen PY, Lin AYM, Seki Y. Biological materials: Structure and mechanical properties. Prog Mater Sci 2008;53(1):1-206.

38. Bigliani LU, Pollock RG, Soslowsky LJ, Flatow EL, Pawluk RJ, Mow VC. Tensile properties of the inferior glenohumeral ligament. J Orthop Res, 1992; 10(2):187-197.

39. Xie Z, Swain MV, Hoffman, MJ. Structural integrity of enamel: experimental and modeling. J Dent Res 2009;88(6):529-533.

40. Schneider GA, He LH, Swain MV. Viscous flow model of creep in enamel. J Appl Phys 2008;103:014701.

41. Guidoni GM, He LH, Schöberl T, Jäger I, Dehm $\mathrm{G}$, Swain MV. Influence of the indenter tip geometry and environment on the indentation modulus of enamel. J Mater Res 2009;24:616625.

42. Carter DR, Hayes WC. The compressive behavior of bone as two-phase porous structure. J Bone Joint Surg Am 1977;59:954-962. 